Múcio Piragibe Ribeiro de Bakker, contra-almirante, ex-secretário da Comissão Interministerial para os Recursos do Mar - CIRM, ex-coordenador do Programa Antártico Brasileiro. Atualmente é diretor de

Hidrografia e Navegação da Marinha.
Múcio Piragibe Ribeiro de Bakker

\title{
A Política Nacional para os Recursos do Mar
}

\section{O uso do mar: um panorama histórico}

Os interesses iniciais: a navegação e a pesca

A Política Nacional para os Recursos do Mar, é a expressão, no Brasil de hoje, de um processo, na verdade, milenar. Refiro-me ao processo de interação homem-meio ambiente e, de modo particular, à interação homem-elemento marinho.

Falar sobre o mar e seus recursos implica em reviver esse processo, que se iniciou praticamente com as atividades de navegação e de pesca, formas naturais e quase instintivas de convívio e de aproveitamento do mar, que se afigurava então, diante da terra, como via de comunicação e troca entre grupos sociais, ao mesmo tempo que fonte suplementar de alimentos.

Tais formas de uso do mar, entretanto, apesar de desenvolvidas durante séculos, levaram apenas a úm conhecimento aleatório do meio marinho e do meio oceânico, então encarados com o mesmo grau de curiosidade e mistério que cerca atualmente os limites do Universo e definido, nas palavras de $\mathrm{Hu}$ go Grotius (1583-1645), como a "expressão do imenso, do infinito, limitado apenas pelos céus, pai de todas as coisas e que realmente mais possui a Terra do que é por ela possuído".

A navegação e suas necessidades foram os motores iniciais da busca sistemática de entendimento do ambiente que, então, se começava a explorar. Não se buscava entender a grande mecânica desse ambiente, mas apenas dele extrair os conhecimentos que permitissem uma navegação ca- paz de fazer chegar aos destinos desejados, onde se obtinham as mercadorias e os alimentos necessários à complementação das exigências da vida nas sociedades da época. Portulanos, cartas de marear, roteiros, bússola e astrolábio, foram expressão e resultado dessa busca pragmática de conhecimento, mais orientada para a familiaridade imediata com a realidade oceânica do que propriamente para atingir as causas que a determinavam.

\section{A origem da oceanografia: navegação e correntes marítimas}

Dominadas as técnicas básicas da navegação oceânica e garantida a possibilidade de se chegar diretamente aos pontos desejados, surgiu a preocupação em fazê-lo mais rapidamente, encurtando rotas e diminuindo travessias. Procurou-se depois utilizar os fenômenos, não apenas evitando aqueles que fossem perigosos, mas aproveitando seus efeitos quando favoráveis à navegação.

Apareceram aí os primeiros estudos mais direcionados para o que se chamaria hoje de pesquisa oceanográfica, isto é, aquela que visa o conhecimento dos fenômenos e de sua mútua interação, mas sem perder de vista uma finalidade imediata; no caso, o aumento da rapidez das travessias oceânicas. Por exemplo, a rapidez das travessias entre Inglaterra e suas colônias na América do Norte pôde ser diminuída em cerca de quinze dias através do conhecimento da Corrente do Golfo, conhecimento este que foi possibilitado inicialmente pelo fato de os pescadores de baleia acompanharem suas presas, 
que normalmente se deslocavam nas bordas dessa corrente.

\section{O conhecimento sistemático do mar: as expedições oceanográficas}

O nascimento da oceanografia, como hoje é entendida, pode ser caracterizado pela expedição do navio inglês "challenger", que deixou o território britânico em 21 de dezembro de 1872 e demorou cerca de três anos e meio em viagem de circunavegação, durante a qual realizou estações de pesquisa que abrangiam não-somente a superfície do mar, mas também a massa d'água subjacente e o solo oceânico, daí resultando, inclusive, a descoberta dos primeiros nódulos polimetálicos.

Outras expedições oceanográficas se sucederam e as amostras recolhidas em estações, subsidiaram estudos voltados para o conhecimento do mar e suas possibilidades.

A curiosidade científica, entretanto, adquiria o caráter de motivação principal, em desfavor da abordagem pragmática que marcara os primeiros estudos sobre o mar.

\section{As conseqüências econômicas da oceanografia para fins militares}

A fase posterior à Segunda Guerra Mundial e a confrontação soviético-americana restauraram o primado do pragmatismo no campo da oceanografia. Entretanto, tratava-se agora de finalidades militares, relativas principalmente à guerra submarina $e$ às operações anti-submarino, suscitando rápidos progressos no domínio da física e mais particularmente no seu ramo da acústica, essencial àqueles tipos de operação. O aparecimento dos submarinos nucleares veio intensificar essa tendência do estudo e da exploração dos oceanos.

No entanto, do próprio incremento da oceanografia para fins militares, resultou, no seu conteúdo, uma visualização mais perfeita das potencialidades econômicas do mar e foi assim que, finalmente, no início da década de 60 , despontou o interesse pela possibilidade de exploração de seus recursos, passando o estudo dos oceanos a ter preferencialmente uma finalidade nitidamente econômica, a par dos propósitos militares e científicos que já se encontravam presentes e que continuam até hoje.

\section{O mar como fonte de riquezas: as possibilidades de hoje}

Os recursos do mar: seus aspectos principais

As riquezas oceânicas podem ser c segundo três aspectos principais que, aliás, caracterizam a atuação brasileira quanto aos recursos do mar: os recursos vivos, os recursos minerais e os energéticos.

As perspectivas de utilização econômica de tais recursos levaram, inclusive, a uma profunda alteração do quadro jurídico de uso do mar que, após inúmeras discussões, culminou com a codificação de uma nova lei do mar, consubstanciada na III Conferência das Nações Unidas sobre o Direito do Mar (outubro de 1982).

\section{Os recursos vivos: a pesca e a maricultura}

Em um mundo que comporta hoje um milhão de subalimentados e onde o espaço terrestre é progressivamente ocupado, torna-se fácil entender a importância do mar como fonte de proteínas.

$\mathrm{Na}$ realidade, o crescente conhecimento do meio ambiente e do uso adequado dos métodos de captura fez com que o volume da pesca mundial triplicasse entre 1950 e 1968 , passando de 21 para 63 milhões de toneladas.

Julgava-se, entretanto, que a possibilidade de contribuição do oceano para o balanço alimentar da humanidade fosse ilimitado. Um equívoco, pois, desde o início da década de 70, a produção mundial de pescado vem aumentando muito lentamente lem 1980 , o volume total atingiu cerca de 70 milhões de toneladas), em grande parte devido ao declínio da produção do Peru, que se havia transformado, a partir de 1957, no primeiro produtor mundial.

Sabe-se que a determinação dos níveis ótimos de captura exige o conhecimento das diversas espécies marinhas, dos seus hábitos migratórios e de sua reprodução, ao mesmo tempo que a diversificação da pesca, através do uso de espécies ainda não aproveitadas normalmente, poderá representar não só uma nova fonte para o incremento da contribuição alimentar prestada pela atividade pesqueira mas, sobretudo, uma maneira de permitir a reposição dos estoques mais procurados e submetidos à pesca predatória

A redução do desperdício seria outra maneira de concorrer para esse objetivo, através do aproveitamento do refugo de peixes capturados e novamente devolvidos ao mar, pelo fato de serem pequenos ou porque pertencem a espécie de pequeno valor comercial, embora aproveitáveis para a alimentação.

Também outras ações poderiam ser desenvolvidas como, por exemplo, o incremento da pesca em regiões ainda pouco exploradas, entre as quais figuIm grandes áreas do Atlântico Sul. A distância en- 
tre estas regiões e os grandes centros de consumo onera os investimentos dificultando a implementação de tais ações.

Além disso, parece residir na maricultura ou aqüicultura, criação artificial de peixes e algas, a solução para aumentar substancialmente a produção dos recursos vivos dos oceanos, pois tal atividade tenderia a substituir a pesca, do mesmo modo que, em terra, a criação extensiva ou intensiva substituiu a caça, mudando totalmente as perspectivas da produção de alimentos.

Enfim, se em terra o homem desenvolveu processos criativos para a utilização dás espécies animais e vegetais para a sua alimentação, preservandoas da caça predatória e até alterando as suas características primitivas, com vistas a aumentar a oferta de alimentos, no mar, ele continuou caçador. As técnicas desenvolvidas visaram mais o aperfeiçoamento dos métodos de captura do pescado e o conhecimento da ocasião mais oportuna economicamente para fazê-la, do que propriamente o estudo de processos que possibilitassem a criação no cativeiro de determinadas espécies marinhas, preferidas para a alimentação humana, o que só recentemente vem acontecendo. Malgrado tais esforços, o homem, no mar, mantém-se um predador, sem maior preocupação preservacionista ou ecológica (para cada tonelada de camarão, pescada por um barco camaroneiro, através da pesca do arrasto, forma predatória da pesca, cerca de aproximadamente cinco toneladas de peixes são devolvidas ao mar e, portanto, desperdiçadas).

Um intenso esforço de pesquisa e de preservação de áreas costeiras é, porém, exigido para se atingir os objetivos da maricultura, de modo a que se consiga, conforme estimativas existentes, dobrar a produção dos recursos vivos, mediante o aproveitamento de apenas $10 \%$ da extensão do litoral apropriado para essa atividade.

Além disso, a criação artificial de espécies marinhas, isto é, maricultura, se propõe também ao repovoamento, com vistas à recomposição dos estoques mais atingidos pela sobrepesca, preservandose assim a cadeia ecológica e, por outro lado, mantendo-se a oferta de alimentos. Paralelamente, isto implicará em sensível aumento de oferta de empregos a curto prazo, com reflexos sociais e econômicos altamente positivos.

De outra parte, a implantação de tais projetos levaria, naturalmente, ao controle de uso dos locais onde eles seriam desenvolvidos, exercendo-se, por conseguinte, uma ação preventiva que evitaria conseqüentemente toda sorte de atividade poluidora e predatória.
Apesar da maricultura representar, indubitavelmente, a solução futura para aumentar a oferta de alimentos provenientes do mar, ela ainda será, pelo menos durante algum tempo, um complemento da pesca extrativa, e o apelo do mar à criação de grandes frotas pesqueiras modernas ainda se fará presente, inclusive em relação às regiões antárticas, onde o "krill" representa uma possibilidade alimentar, em constante pesquisa e avaliação pela comunidade científica internacional.

Ressalte-se, finalmente, que o Atlântico Sul, sobretudo na sua porção ocidental, era, em 1970, a área de maior potencial inexplorado de pesca (Ocean Yearbook, 1978, p. 51) e essa situação não mudou sensivelmente, a partir daquela data. Quem se refere ao Atlântico Sul, também se refere ao Brasil e mais ainda quando se trata da parte que lhe é contígua. Reflexões dessa ordem pedem um posicionamento dos brasileiros, aspecto que pretendo abordar ao final destas considerações.

\section{Os recursos minerais: o petróleo, outros minerais e os nódulos polimetálicos}

\section{O petróleo}

Se sempre foi grande e conhecida a possibilidade de utilização da oferta alimentar proveniente do oceano, é muito mais recente e mais espetacular o crescimento da produção mineral de origem marinha.

A produção de petróleo, provindo de poços marítimos, quadruplicou entre 1960 e 1973, data em que já representava $18 \%$ da produção mundial. A partir de então e até 1979, essa participação passou a $20 \%$, embora tivesse havido um aumento da ordem de $50 \%$ na produção marítima.

No Brasil, entre 1970 e 1978, a produção marítima de petróleo tornou-se quase cinco vezes maior, passando de 8 milhões para 38,9 milhões de barris. Atualmente, no mar, a produção brasileira de petróleo já suplantou a produção em terra. Em uma produção total, no ano de 1982, de cerca de 97 milhões de barris de petróleo, 46 milhões foram extraídos de poços terrestres e 51 milhões aproximadamente de poços marítimos da plataforma continental.

A apreciação desses números faz entender os motivos pelos quais o petróleo se transformou, em curto prazo, no mais importante dentre os setores de exploração dos oceanos. Nesse setor, o alto custo da prospecção e exploração tem sido compensado pela elevação dos preços e relativa escassez do produto, em passado recente.

Projeções feitas em 1980 indicam que o petróleo se tornará um recurso progressivamente mais es- 
casso e mais caro, incapaz de atender, por volta do ano 2.000 , à demanda de energia que dele se exigirá.

Deve-se assinalar que a exploração de petróleo em poços submarinos tem produzido grande incremento da indústria marítima especializada na construção de plataformas e no ramo de transporte e apoio, constituindo um poderoso estímulo para as atividades marítimas como um todo.

Em um Brasil que tem buscado no mar as suas fontes próprias de hidrocarbonetos, cabe indicar e aproveitar essa possibilidade de expansão das atividades complementares à exploração petrolífera, a fim de se obter que elas acompanhem sempre esse bem-sucedido avanço em direção ao oceano.

\section{Outros minerais e os nódulos polimetálicos}

Diversos minerais são, também, extraídos em áreas marítimas, embora essa atividade seja exercida por apenas alguns poucos países.

Neste artigo, à guisa de exemplo, pareceramme interessantes algumas informações sobre os nódulos polimetálicos.

Trata-se uma das mais fascinantes possibilidades de exploração de recursos minerais nos oceanos. Os nódulos polimetálicos são formações quase esféricas, de cor enegrecida e de tamanho e peso variáveis. Em média medem de 4 a 6 centímetros e pesam entre 50 e 100 gramas. Entretanto, alguns nódulos podem ter tamanho e peso consideráveis. Já se colheu no Pacífico um nódulo de 55 quilos.

Os nódulos constituem concreções hidratadas de bióxido de manganês, contendo ainda quantidades menores de níquel, cobre, cobalto e muitos outros elementos metálicos e são formados pela precipitação coloidal do manganês da água do mar, em locais de sedimentação muito lenta, através do processo de aglomeração de partículas. Suas jazidas lembram imensos campos de seixos e săo abundantes na parte inferior do talude continental e nos fundos abissais, em profundidades compreendidas entre 400 e 8.000 metros, ocorrendo em todos os oceanos.

Os recursos minerais que poderiam ser obtidos desses nódulos representariam certamente dezenas de anos de reservas de manganês, níquel e cobalto.

\section{Os recursos energéticos}

Dentre os recursos do mar, os energéticos são, no momento, os menos expressivos, em termos de contribuição global para a economia e poderiam ser caracterizados como provenientes das marés, das ondas, correntes e do gradiente térmico.

O uso das marés é o método mais viável de ge- ração e, atualmente, a França dispõe de uma usina maremotriz importante, mas, ainda assim, o potencial energético das marés seria sempre complementar, e em pequena escala, às fontes de energia tradicionais.

Outros métodos de geração projetados, ainda não foram colocados em uso, devido às dificuldades técnicas e custos envolvidos.

\section{Os recursos do mar no Brasil: o horizonte político e técnico-científico}

O painel até aqui traçado permite vislumbrar para o Brasil um grande campo de atuação em relação aos seus recursos marinhos.

O incremento das atividades e perspectivas do uso do mar e do seu subsolo modificaram o tipo de convivência entre a nação brasileira e o meio oceânico em que está inserida. Modificou-se, também, a visão mundial do problema, desencadeando, através da Conferência das Nações Unidas sobre o Direito do Mar, uma complexa tentativa de regular as situações que poderão advir da nova conjuntura.

\section{As limitações técnico-científicas}

Paralelamente a essa nova situação, no Brasil há diversas limitações a serem superadas.

A simples menção do potencial de pesca inexplorado nas águas adjacentes ao Brasil faz antever o pouco aproveitamento dos recursos vivos no nosso país, conseqüente das carências do setor pesqueiro.

Ao mesmo tempo, verifica-se que o setor de pessoal ligado à exploração dos recursos do mar se ressente de sérias deficiências, que poderiam ser assim resumidas: seleção inadequada; grande predominância da formação em biologia e presença quase nula da formação em química; disparidade de currículos de formação; emprego de pessoal com pósgraduação em pesquisas de utilidade discutível; e dificuldade de intercâmbio de informações.

Quanto ao apoio oceanográfico, o material técnico de origem nacional é quase inexistente, faltam meios flutuantes ou são inadequados. São apenas quatro navios oceanográficos, um quase cinqüentenário e uns poucos barcos, totalmente desequipados.

\section{As limitações políticas: a delimitação da margem continental}

A nova realidade jurídica, criada pela Conferência sobre o Direito do Mar, condiciona o exercício da jurisdição sobre a plataforma continental à caracterização da margem continental que a limita. 
Essa determinação exige uma atuação multidisciplinar, que deve ser feita em prazo de dez anos, além de estar submetida à apreciação de um grupo técnico de alto nível.

Na realidade, o exercício, pelo Brasil, da soberania sobre os fundos marinhos que lhe couberem, fora da zona econômica exclusiva, exige a delimitação da margem continental, tarefa que será realizada, provavelmente, nos próximos anos.

\section{A CIRM e a Política Nacional para os Recursos do Mar como instrumentos de eliminação de carências}

Na década de 60 alguns países já haviam sentido a necessidade de criar organismos coordenadores da atividade científica no mar: a Inglaterra criou, em 1965, o Conselho para o Meio Ambiente; nos Estados Unidos, em 1966, criou-se o Conselho Nacional para os Recursos do Mar e na França em 1967. o Centro Nacional para a Exploração dos Oceanos - CNEXO.

No Brasil, foi criada, em 1974, a Comissão Interministerial para os Recursos do Mar-CIRM, que tem como principais funções assessorar o presidente da República na formulação da Política Nacional para os Recursos do Mar - PNRM e avaliar continuamente o resultado de estudos e pesquisas no setor de sua competência.

Através da PNRM, aprovada em 1980, ficaram fixados os objetivos básicos do setor de recursos do mar. Ainda que não seja caso de enumerá-los, vale lembrar que trata-se de um elenco de propostas que, tendo como fio condutor o interesse pelos recursos do mar, é bastante abrangente, posto que enfoca aspectos jurídicos, educacionais, científicos e tecnológicos, dentre outros.

Para a consecução destes objetivos e visando uma ação efetiva e coordenada do esforço nacional para alcançá-dgs, o governo federal, através da CIRM, se reservou o direito de orientar, coordenar e controlar col exclusividade todas as atividades correspondentes, sempre norteadas no sentido da conservação dos recursos vivos e de preservação ambiental e ecológica.

\section{O I Plano Setorial para os Recursos do Mar-IPSRM}

Esse plano, consubstanciado em cinco programas específicos, é o documento que busca viabilizar a consecução dos objetivos da PNRM, através da definição dos interesses básicos do Brasil no mar, quais sejam: alimentos, matérias-primas e energia.
Os dois primeiros programas (Sistemas Oceânicos e Sistemas Costeiros) visam proporcionar o conhecimento do ambiente marinho, de modo a favorecer o Programa de Recursos do Mar (que abrange os recursos vivos, os minerais e os energéticos), enquanto que os dois últimos, Recursos Humanos e Apoio Oceanográfico, visam prover os meios indispensáveis ao desenvolvimento dos demais.

Note-se que todos os programas convergem para o que se poderia chamar de programa-fim, o de Recursos do Mar, e nesse programa o setor de recursos vivos tem assumido a parcela principal, através principalmente da pesquisa relativa às espécies consideradas prioritárias nas diversas regiões brasileiras.

Os programas ligados ao conhecimento científico do ambiente marinho podem contribuir colateralmente para finalidades militares como as operações submarinas e anti-submarinas.

Convém mencionar que, no Programa de Recursos do Mar, não considera a pesquisa de novas fontes de hidrocarbonetos, atividade que vem sendo desenvolvida diretamente pelo Ministério das Minas e Energia, através da Petrobrás.

Deve-se também mencionar as atividades de gerenciamento costeiro, como essenciais ao desenvolvimento das atividades de maricultura.

Este gerenciamento costeiro deverá levar em conta categoria de problemas como aqueles que surgem das interações entre as diferentes atividades de desenvolvimento, os que decorrem das modificações dos processos costeiros ou as da destruição de unidades ambientais críticas e os derivados da poluição das águas costeiras e estuarinas.

No corrente exercício, a execução do I PSRM recebeu o seu primeiro orçamento no valor de 2,3 bilhões de cruzeiros.

\section{As perspectivas do futuro}

Diante desse panorama, e do relativo vazio de atividade humana que ainda reina no Atlântico Sul, cabe ao Brasil aćeitar o desafio do mar, que lhe é veementemente apresentado.

A busca de recursos, sobretudo alimentares e minerais, é parte substancial da resposta a esse desafio.

Se a marinha assumiu responsabilidade nesse campo, aparentemente alheio à sua atividade principal, ela o fez principalmente como elemento catalizador e coordenador de um esforço que é e será, cada vez mais, desenvolvido por organizações civis: universidades, instituições científicas e, também, por empresas nacionais. 
Os custos envolvidos e as perspectivas abertas pela pesquisa, exploração e explotação dos recursos do mar sugerem que essas atividades sejam permeadas pelos requisitos de intencionalidade e racionalidade.

Estes fatores presidem as definições de projetos e as necessárias revisões do Plano Setorial para os Recursos do Mar, documento que, como se viu, é a forma de viabilização da política nacional. O desenvolvimento desse plano gera um processo amplo e participativo, de caráter ao mesmo tempo científico e utilitário, jamais de cunho predominantemente militar, mas que, envolvendo amplamente a comunidade nacional, procura traçar o caminho mais direto do Brasil em direção à plena utilização do mar e à realização prática das suas potencialidades. 